\title{
Natural vs synchronized estrus: determinants of successful pregnancy in ewes using frozen-thawed Suffolk semen
}

\author{
Md. Mahbubur Rahman, Nazmun Naher, Md. Mofijul Isam, Moinul Hasan, Farhana Naznin, \\ Mohammad Musharraf Uddin Bhuiyan, Farida Yeasmin Bari and Nasrin Sultana Juyena* \\ Department of Surgery and Obstetrics, Faculty of Veterinary Science, Bangladesh Agricultural University, \\ Mymensingh-2202, Bangladesh
}

Received May 19, 2020

Revised June 8, 2020

Accepted June 8, 2020

\section{*Correspondence}

Nasrin Sultana Juyena

E-mail: nsjuyena@bau.edu.bd

ORCID

https://orcid.org/0000-0003-0331-0998

\begin{abstract}
The pregnancy rate in indigenous ewes inseminated with frozen-thawed Suffolk semen following natural and synchronized estrus was determined. The serum Progesterone and Estrogen concentration and vaginal electrical resistance (VER) of ewes at the time of Artificial Insemination (Al) were observed as successful pregnancy determinants. 21 healthy ewes were selected for this experiment during JanuaryApril, 2017. 10 ewes were inseminated in natural estrus. Whereas, 11 ewes were inseminated after estrus synchronization using intravaginal sponges containing 60 mg medroxyprogesterone acetate. Trans-cervical Al (TCAI) was performed in all ewes within 12-16 hours of observed heat. Prostaglandin $E_{1}$ analogue impregnated vaginal sponge was used for cervical relaxation 6-8 hours before insemination. Pregnancy was diagnosed through trans-abdominal ultrasonography after 40 days of Al. The pregnancy rate of ewes in synchronized estrus was higher (54.5\%) than in natural estrus (30\%). Higher serum Progesterone level $(0.90 \pm 0.02 \mathrm{ng} / \mathrm{mL})$ and significantly $(p<0.001)$ lower VER $(257.78 \pm 10.11 \mathrm{ohm})$ were observed at the time of Al in ewes becoming pregnant. Results suggest that higher Progesterone concentration and lower VER could be considered as pregnancy indicators. Oestrous synchronization could be implemented to increase the pregnancy rate in ewes.
\end{abstract}

Keywords: estrus, pregnancy rate, progesterone, vaginal electrical resistance (VER)

\section{INTRODUCTION}

Sheep is an important animal among the livestock species. There are about 3.537 million sheep (DLS, 2019) in Bangladesh. However, native sheep is small in body size with poor genetic merit. Most of these sheep are nondescript indigenous type, with few crossbreds (Bhuiyan, 2006). Suffolk is an ideal mutton sheep with large body size, plenty of muscle, good foraging ability and highly resistant to footrot. One of the paramount assisted reproductive technologies is the artificial insemination (AI) which is used to increase reproductive capacity and facilitates the genetic improvement in farm animals (Kwon et al., 2017; Lim and Yoon, 2018; Barsuren et al., 2019; Harun-Or-Rashid et al., 2019). The use of AI based on frozen-thawed semen can significantly increase the number of offspring produced per sire per year because a ram has the potential to produce enough spermatozoa to 
inseminate thousands of ewes. However, lower fertility is obtained when frozen-thawed semen is used for cervical insemination in sheep. The alternative, laparoscopic $\mathrm{AI}$, is an effective method of insemination with frozenthawed semen with the fertilization rates of about $75-80 \%$ (Fukui et al., 2010), but its relative high cost and requirement of skilled surgeon or technician has limited the use of this technique by the sheep breeders. Efficient estrus detection is essential for a successful breeding program. Oestrous synchronization is a valuable management tool which has been successfully employed to enhance reproductive efficiency, particularly in ruminants (Kusina et al., 2000). Intravaginal sponges and other devices have been effectively used for synchronization of oestrous and ovulation during the breeding and nonbreeding season with gonadotrophin treatment in ewes (Hill et al., 1998). Measurement of vaginal electrical resistance (VER) is a useful tool for oestrus detection, ovulation and appropriate time of mating or insemination (Gupta and Purohit, 2001). When used correctly, vaginal resistance could be a very viable indicator of a successful pregnancy. Therefore, this study was aimed to observe and compare the pregnancy rates following natural and synchronized estrus through trans-cervical artificial insemination (TCAI) of ewes with frozen-thawed Suffolk semen. The effect of Progesterone and Estrogen concentration and VER values of ewes at the time of AI on successful pregnancy determination was also observed.

\section{MATERIALS AND METHODS}

\section{Ethical approval}

The research was designed following the U.K. Animals (Scientific Procedures) Act, 1986 and associated guidelines, EU Directive 2010/63/EU for animal experiments. The Animal Experimentation Ethics Committee (AEEC), Department of Surgery and Obstetrics, Bangladesh Agricultural University approved the study design on ewes (Protocol Number: 01/2017/AEEC).

\section{Experiment location}

The research was conducted at the Research Animal Farm (RAF), Department of Surgery and Obstetrics, Faculty of Veterinary Science, Bangladesh Agricultural University, Mymensingh 2202, Bangladesh and at the Rural Development Academy (RDA), Bogra, Bangladesh during
January to April 2017.

\section{Selection and management of ewes}

21 healthy ewes were randomly selected for this experiment. Both trans-rectal and trans-abdominal ultrasonography were performed to select these non-pregnant ewes. The ewes were in the regular oestrous cycle. The age and bodyweight of the selected ewes ranged from 1-2 years and 16-18 kg, respectively. Ewes were kept in separate pens away from the rams. The ewes were housed in a covered shelter with open-air ventilation and were allowed 6-8 hours natural grazing. Each ewe was fed approximately $300 \mathrm{~g}$ concentrate (Wheat bran, maize grit, wheat polish with salt) daily. Regular deworming and vaccination available in Bangladesh were performed to the animals. Ewes were divided into two groups. Ewes of Group N ( $n=10)$ were inseminated after observing natural estrus. Whereas, ewes of Group S $(n=11)$ were inseminated after estrus synchronization.

\section{Estrus synchronization}

Ewes were treated with intravaginal sponges containing $60 \mathrm{mg}$ medroxyprogesterone acetate (OVIGEST ${ }^{\circledR}$, Laboratories Hipra, Spain) for 14 days. Then, ewes were injected intramasularly with 300 IU PMSG (folligon ${ }^{\circledR}$, Intervet Boxmeer, the Netherlands) at sponge removal in order to induce and synchronize estrus.

\section{Heat detection}

Estrus was detected by using a vasectomized ram introduced for a period of 20 min twice daily (early morning and late evening). The signs of heat included restlessness, seeking for males, sexual receptivity, swelling and redness of the vulva, waggling of the tail and when approached by the male, standing for teasing and permitting mount attempts.

\section{Determination of vaginal electrical resistance (VER)}

The VER values were determined before insemination using electronic heat detector (DRAMINSKI ${ }^{\circledR}, 17$ Owocowa, Poland) by following the method described by Talukder et al. (2018). After restraining the ewes, the vulva of the animals was soaked with a mild antiseptic solution. The DRAMINSKI ${ }^{\circledR}$ heat detector was prepared after cleaning the probe with a mild antiseptic (1\% Potassium Permanganate solution). Heat detector was then inserted 
into the vagina and was placed aside to the vaginal wall to take the reading. The VER value was determined as per instruction of the manufacturer, and the average value of three consecutive measurements was recorded.

\section{Process of $\mathrm{Al}$}

Trans-cervical Al (TCAI) was performed in all natural and synchronized ewes within 12-16 hours of first observed heat. After the detection of heat, ewes were treated with prostaglandin $\mathrm{E}_{1}$ analogue (Misoprostol) impregnated vaginal sponge for cervical relaxation for 6-8 hours prior to insemination. For that purpose, two pills of Misoprostol (200 $\mu$ g Cytomis $^{\circledR}$, Incepta Pharmaceuticals, Bangladesh) was powdered and mixed to 1-2 drops of glycerol. Frozenthawed New Zealand Suffolk semen was used for TCAI. Semen was stored at $-196^{\circ} \mathrm{C}$ liquid Nitrogen. Before AI, the Misoprostol impregnated vaginal sponge was removed, and the vagina was cleaned with a clean tissue. Prior to insemination, straws were thawed at $37^{\circ} \mathrm{C}$ for $30 \mathrm{sec}$ and then loaded in the AI gun. The cervix was grasped with forceps and retracted partly into the vagina to locate the cervical opening. The AI gun was then inserted into the cervix and pushed forward as much as it passes easily through the rings. Then the semen was expelled deep into the cervix by depressing the plunger. After deposition of semen, the AI gun was kept in position for 2 min before withdrawn from the cervix. The same operator performed AI.

\section{Pregnancy diagnosis}

All inseminated ewes were monitored for non-return to estrus by the aid of a vasectomized teaser ram at 14-17 days following insemination. The ewes which didn't show estrous were allowed for trans-abdominal ultrasonography scanning for confirmation of pregnancy using YSVET0206 Veterinary Ultrasound Machine with transducer frequency $6.5 \mathrm{mHz}$ within $40-50$ days post insemination.

\section{Measurement of serum progesterone and estradiol concentration}

Blood sample $(3 \mathrm{~mL})$ was collected at the time of AI with appropriate aseptic measures from jugular vein without using anticoagulant. Then serum was prepared and stored at $-20^{\circ} \mathrm{C}$ until analysis by ELISA for measurement of the concentration of Progesterone and Estradiol hormone. Then the samples were assayed by ELISA technique using Progesterone and Estradiol ELISA kit.
Concentration was calculated using the formula $\mathrm{y}=$ $-0.336 \ln (x)+2.5588$ for Estradiol and $y=-0.154 \ln (x)+$ 0.7864 for Progesterone obtained from standard value curve.

\section{Statistical analysis}

VER values and hormonal measurement (Progesterone and Estradiol concentration) were expressed as Mean \pm Standard Error (SE). Comparison of pregnancy rate between insemination in natural and synchronized ewes was performed using one-way analysis of variance (ANOVA). Pearson's correlation was performed to study the relationship among parameters. All the statistical analyses were done using SPSS 20.0. The difference between groups was regarded as significant when the $p$-value was less than $0.05(p<0.05)$.

\section{RESULTS}

\section{Pregnancy rates in ewes}

The success of TCAI was monitored through pregnancy rates. The overall pregnancy rates were $42.8 \%$. Non-return rates were $40 \%$ and $81.8 \%$, and pregnancy rates were $30 \%$ and $54.5 \%$ in ewes following natural and synchronized estrus respectively. Hence, both non-return and pregnancy rates following TCAI of synchronized oestrous were significantly $(p<0.05)$ higher.

\section{Changes in progesterone and estrogen concentration}

After TCAI in synchronized estrus group, Progesterone concentration in ewes becoming pregnant was $0.90 \pm 0.02$ $\mathrm{ng} / \mathrm{mL}$ which is significantly higher $(p<0.05)$ compared to $0.82 \pm 0.02 \mathrm{ng} / \mathrm{mL}$ in ewes remaining non-pregnant (Fig. 1). In ewes which have become pregnant, Progesterone concentration was significantly higher $(p<0.05)$ in synchronized estrus group $(0.90 \pm 0.02 \mathrm{ng} / \mathrm{mL})$ than in natural estrus group $(0.82 \pm 0.02 \mathrm{ng} / \mathrm{mL})$. However, there was no significant $(p<0.05)$ difference in serum Estrogen concentration (Fig. 2) between ewes becoming pregnant $(2.40 \pm 0.02 \mathrm{pg} / \mathrm{mL}$ and $2.53 \pm 0.04 \mathrm{pg} / \mathrm{mL})$ and those remaining non-pregnant $(2.42 \pm 0.03 \mathrm{pg} / \mathrm{mL}$ and $2.53 \pm 0.03$ $\mathrm{pg} / \mathrm{mL}$ ) in both natural and synchronized estrus (respectively). Results reveal that synchronization with medroxyprogesterone (MGA) sponge has a positive effect on serum Progesterone level, which might be helpful to maintain pregnancy. 


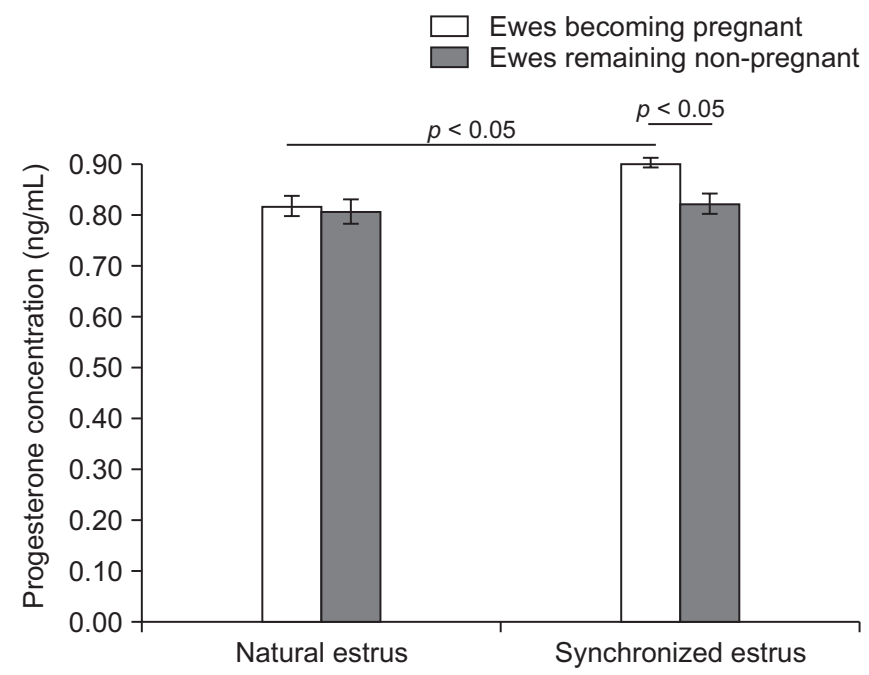

Fig. 1. Serum progesterone concentration at the time of $\mathrm{Al}$ in natural and synchronized estrus. The vertical axis denotes Progesterone concentration $(\mathrm{ng} / \mathrm{mL})$. Values are represented as mean $\pm \mathrm{SE}$.

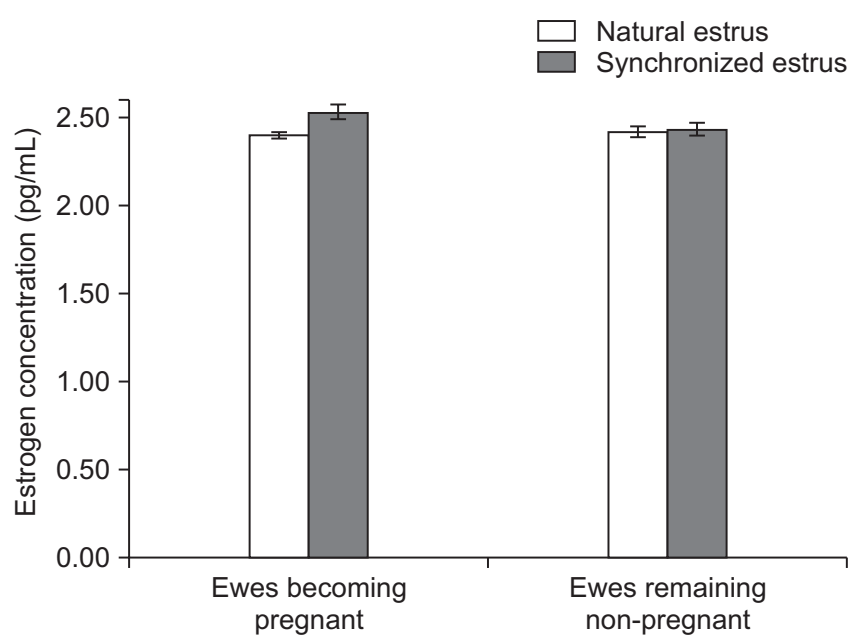

Fig. 2. Serum estrogen concentration at the time of Al in natural and synchronized estrus. The vertical axis denotes Estrogen concentration $(\mathrm{pg} / \mathrm{mL})$. Values are represented as mean $\pm \mathrm{SE}$.

\section{Changes in vaginal electrical resistance (VER) values}

Vaginal electrical resistance (VER) was found to be significantly $(p<0.001)$ lower at the time of TCAI in ewes becoming pregnant $(276.67 \pm 06.67 \mathrm{ohm}$ and $248.33 \pm$ $13.52 \mathrm{ohm})$ in comparison to ewes remaining non-pregnant $(397.14 \pm 13.58 \mathrm{ohm}$ and $338.00 \pm 10.20 \mathrm{ohm})$ with natural and synchronized estrus (respectively). All pregnant ewes showed VER values $<300 \mathrm{ohm}$ at the time of AI (Fig. 3).

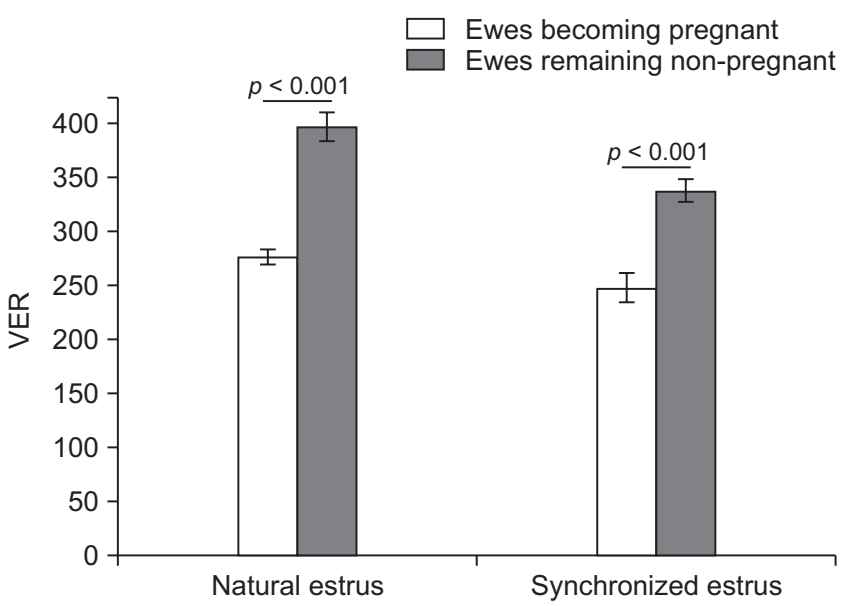

Fig. 3. Vaginal electrical resistance (VER) values at the time of $\mathrm{Al}$ in natural and synchronized estrus. The vertical axis denotes VER values (ohm). Values are represented as mean \pm SE.

Table 1. Pearson's correlation among serum progesterone, estrogen, and VER values of pregnant and non-pregnant ewes

\begin{tabular}{lcccccc}
\hline & \multicolumn{2}{c}{ Non-pregnant ewes } & & \multicolumn{2}{c}{ Pregnant ewes } \\
\cline { 2 - 3 } \cline { 5 - 6 } & Estrogen & VER & & Estrogen & VER \\
\hline Progesterone & 0.72 & 0.10 & & 0.60 & -0.32 \\
Estrogen & - & -0.04 & & - & -0.62 \\
\hline
\end{tabular}

The values between -1 and 1 correspond to the linear relationship between the two variables. The further away the value is from zero, the stronger the linear relationship between the two variables. +/- sign indicates the direction of the relationship. If the value is positive, then as one variable increases, the other tends to increase. If the value is negative, then as one variable increases, the other tends to decrease. A perfect linear relationship $(=-1$ or $=+1)$ means that one of the variables can be perfectly explained by a linear function of the other.

\section{Correlation among progesterone, estrogen, and VER values of pregnant and non-pregnant ewes}

Pearson's correlation among Progesterone, Estrogen, and VER values of pregnant and non-pregnant ewes showed that a positive relationship existed between progesterone and Estrogen concentration of both pregnant and non-pregnant ewes. However, this relation was very strong in non-pregnant ewes (Table 1). An insignificant negative relation of VER with serum Progesterone and Estrogen level was observed in ewes becoming pregnant. Correlation results indicate that Progesterone level at the time of AI might play an important role on successful pregnancy and lower VER values at the time of AI could be used as indicator of successful pregnancy. 


\section{DISCUSSION}

Sustainability of AI techniques with high pregnancy rates may allow its routinely use in ewes to facilitate and enhance genetic improvement programmes of sheep breeding in Bangladesh. Generally, sheep breeds reared in tropical $\left(23^{\circ} \mathrm{N}-23^{\circ} \mathrm{S}\right)$ or subtropical (around $24^{\circ} \mathrm{N}-34^{\circ} \mathrm{N}$; $\left.24^{\circ} \mathrm{S}-34^{\circ} \mathrm{S}\right)$ areas have a long breeding season as no strong seasonal changes in photoperiod cues are observed in them. Being a tropical country, the indigenous ewes of Bangladesh usually show estrus across the year with no anovulatory period (Yenikoye, 1984; Gonzalez et al., 1992; Arroyo et al., 2007).

The average non-return rate $(61.9 \%)$ and pregnancy rate (42.8\%) obtained after TCAI with frozen-thawed semen in this study were higher than that (10-15\%) observed by Kershaw et al. (2005) and lower in comparison to that (5776\%) reported by Windsor (1995). Donovan et al. (2004) reported a $58 \%$ non-return rate following deep cervical insemination with Frozen-thawed semen. However, TCAI has a limitation due to the complex anatomy of the ovine cervix (Rashidi and Cedden, 2013). TCAI involves grasping the cervix with forceps and retracting it partly into the vagina, in order to introduce the insemination probe. This retraction and manipulation of the cervix could damage the tissue surrounding the cervical os, and cause trauma and haemorrhage, which potentially reduce the fertility of the ewes (Halbert et al., 1990). Therefore, Misoprostol, a synthetic analogue of prostaglandin $\mathrm{E}_{1}\left(\mathrm{PGE}_{1}\right)$, was used to relax and dilate the cervix. Misoprostol causes cervical ripening and the occurrence of rapid uterine smooth muscle contraction. Leethongdee et al. (2007) evaluated the usefulness of Misoprostol and found that treated intracervical with $1 \mathrm{mg}$ of Misoprostol dissolved in $0.5 \mathrm{~mL}$ of $30 \%$ gelatin showed good fertility. However, cervical dilatation was not evaluated after misoprostol treatment. The differences in the pregnancy rate observed in different studies might be due to the differences in body condition, breed of experimental animals, management systems and the season, in which the studies were done (Horoz et al., 2003; Timurkan and Yildiz, 2005; Zeleke et al., 2005). However, the fertility of frozen-thawed semen can be increased by increasing concentration of spermatozoa in the inseminate, treatment of ewes with hormones to relax the cervix, modification of the diluents for semen storage and double AI (Salamon and Maxwell, 1995).
Results revealed higher pregnancy rate $(54.5 \%)$ in ewes synchronized with medroxyprogestrone acetate (MAP) sponge and PMSG and a positive effect of synchronization on serum Progesterone concentration (Fig. 1), which might help to maintain pregnancy. Exogenous Progesterone acts in the same way as a corpus luteum does, resulting in a negative feedback effect upon the anterior pituitary. When the source of Progesterone is withdrawn, or its effect declines, there is a return to cyclic activity ( $\mathrm{No}^{-}$ akes, 2001). Hormonal treatment with Progesterone and PMSG has been successfully utilized as a method for inducing estrus and ovulation in seasonally anestrous ewes (Kusakari et al., 1995). Langford et al. (1983) reported that Progesterone and gonadotrophin were used to synchronize estrus and increase ovulation in different breeds of sheep. When intravaginal Progesterone devices are used, it is necessary to use PMSG at the end of the Progesterone priming period (Noakes, 2001). PMSG increased the total Progesterone in ewes treated with fluorogestone acetate (FGA) due to the increase in the number of ovulation (Hackett and Hidiroglou, 1983). Hill et al. (1998) observed a higher pregnancy rate in synchronized ewes treated with Folligon (PMSG). Moreover, Theodosiadou et al. (2014) have stated that Progesterone concentration during estrus is a critical parameter concerning whether the ewe has conceived or not.

VER values just before TCAI were significantly $(p<0.001)$ lower in ewes that conceived compared to those that did not conceive irrespective of natural or synchronized estrus (Fig. 3). This finding corresponds well with that of Theodosiadou et al. (2014) and Tsiligianni (2014). All ewes were detected in estrus by teaser rams, while only those with the electrical resistance of vaginal mucus $<300 \mathrm{ohm}$ finally conceived. Tsiligianni (2014) has reported that cervical mucus volume and crystallization are increased after estrus synchronization by MGA in ewes and these differences could be reflected to electrical resistance of cervical mucus. He has also stated a good relation of low electrical resistance of cervical mucus in pregnant ewes with better sperm transformation and survival of spermatozoa into the cervix. It is worthy to state that VER showed a negative correlation with serum Progesterone and Estrogen level at the time of AI in this study (Table 1). This finding supports the reports by Ginther et al. (2005). They have stated that follicular development is accompanied by an elevation in plasma estradiol level that helps to induce 
female receptivity and a decrease in vaginal impedance. A close association between the lowest value of vaginal impedance during the follicular phase of the oestrous cycle and manifestations of oestrous behaviour was observed in many species, and resistances are also known to be under the influence of Estrogen and Progesterone (Rezac, 2008). Thus, the electrical resistance of cervical mucus could provide useful information about the development of preovulatory antral follicles in ewes. VER throughout the oestrous cycle decreases gradually in the follicular phase. It reaches the lowest value in sheep (Bartlewski et al., 1999) during pro-estrus and estrus. During estrus, the concentration of Estrogen rises, causing an increase in adrenocorticotropic hormone and aldosterone. These hormones increase the levels of $\mathrm{NaCl}$ in vaginal mucus, which decreases electrical resistance (Fehring, 1996). Hence Low VER values of the cervical mucus at the time of TCAI could be a valuable indicator for prediction of successful conception in ewes.

\section{CONCLUSIONS}

The study concludes that higher pregnancy rate can be obtained following TCAI after synchronization of estrus. Higher Progesterone concentration at the time of AI plays a vital role in successful conception. VER values $<300$ ohm at the time of AI can be used as an indicator of successful pregnancy in ewes.

\section{CONFLICTS OF INTEREST}

No potential conflict of interest relevant to this article was reported.

\section{ACKNOWLEDGEMENTS}

The research work was funded by the World Bank through the Higher Education Quality Enhancement Project (HEQEP) of the University Grants Commission of Bangladesh (HEQEP sub-project CP-3015).

\section{AUTHOR CONTRIBUTIONS}

Rahman MM, Naher N, and Isam MM designed and executed the experiment, collected data and drafted the manuscript.
Hasan $\mathrm{M}$ analyzed data and drafted the manuscript.

Naznin F executed the experiment and performed data collection.

Bhuiyan MMU and Bari FY critically reviewed the manuscript and provided valuable suggestions.

Juyena NS designed the experiment and supervised throughout the research activities.

\section{AUTHOR'S POSITION AND ORCID NO.}

\author{
MM Rahman, Researcher, \\ https://orcid.org/0000-0002-5465-4494 \\ N Naher, Lecturer, \\ https://orcid.org/0000-0002-9583-458X \\ MM Isam, Ph.D Student, \\ https://orcid.org/0000-0001-5186-2004 \\ M Hasan, Assistant Professor, \\ https://orcid.org/0000-0001-9994-9555 \\ F Naznin, Researcher, \\ https://orcid.org/0000-0002-2060-320X \\ MMU Bhuiyan, Professor, \\ https://orcid.org/0000-0002-0870-186X \\ FY Bari, Professor, \\ https://orcid.org/0000-0003-1358-460X \\ NS Juyena, Professor, \\ https://orcid.org/0000-0003-0331-0998
}

\section{REFERENCES}

Arroyo LJ, Gallegos-Sánchez J, Villa-Godoy A, Berruecos JM, Perera G, Valencia J. 2007. Reproductive activity of Pelibuey and Suffolk ewes at 19 degrees north latitude. Anim. Reprod. Sci. 102:24-30.

Barsuren E, Kim SH, Lee HJ, Yoon JT. 2019. Effect of embryo transfer seven days after artificial insemination with sexed and conventional semen from superovulated cattle. J. Anim. Reprod. Biotechnol. 34:106-110.

Bartlewski PM, Beard AP, Cook SJ, Chandolia RK, Honaramooz A, Rawlings NC. 1999. Ovarian antral follicular dynamics and their relationships with endocrine variables throughout the oestrous cycle in breeds of sheep differing in prolificacy. J. Reprod. Fertil. 115:111-124.

Bhuiyan AKFH. 2006. Livestock genetic resources in Bangladesh: Preservation and Management. International conference on livestock services, Chinese Academy of Agricultural Science 16-20.

DLS. 2019. Livestock Economy at a Glance 2018-2019. Directoate of Livestock Services, Ministry of Fisheries and Livestock, Government of the People's Republic of Bangladesh. Available 
at https://dls.portal.gov.bd/sites/default/files/files/dls.portal.gov.bd/page/ee5f4621_fa3a_40ac_8bd9_898fb8ee4700/ Updated\%20Livestock\%20Economy\%20\%20\%2820182019\%29.doc.

Donovan A, Hanrahan JP, Kummen E, Duffy P, Boland MP. 2004. Fertility in the ewe following cervical insemination with fresh or frozen-thawed semen at a natural or synchronised oestrus. Anim. Reprod. Sci. 84:359-368.

Fehring RJ. 1996. A comparison of the ovulation method with the CUE ovulation predictor in determining the fertile period. J. Am. Acad. Nurse Pract. 8:461-466.

Fukui Y, Kohno H, Okabe K, Katsuki S, Yoshizawa M, Togari T, Watanabe H. 2010. Factors affecting the fertility of ewes after intrauterine insemination with frozen-thawed semen during non-breeding season. J. Reprod. Dev. 56:460-466.

Ginther OJ, Gastal EL, Gastal MO, Beg MA. 2005. Regulation of circulating gonadotropins by the negative effects of ovarian hormones in mares. Biol. Reprod. 73:315-323.

Gonzalez A, Murphy BD, Foote WC, Ortega E. 1992. Circannual estrous variations and ovulation rate in Pelibuey ewes. Small Rumin. Res. 8:225-232.

Gupta KA and Purohit GN. 2001. Use of vaginal electrical resistance (VER) to predict estrus and ovarian activity, its relationship with plasma progesterone and its use for insemination in buffaloes. Theriogenology 56:235-245.

Hackett AJ and Hidiroglou M. 1983. Effects of PMSG on progesterone levels in ewes treated with fluorogestone acetate or prostaglandin F2 $\alpha$. Anim. Reprod. Sci. 6:191-197.

Halbert GW, Dobson H, Walton JS, Sharpe P, Buckrell BC. 1990. Field evaluation of a technique for transcervical intrauterine insemination of ewes. Theriogenology 33:1231-1243.

Harun-Or-Rashid M, Sarkar AK, Hasan MMI, Hasan M, Juyena NS. 2019. Productive, reproductive, and estrus characteristics of different breeds of buffalo cows in Bangladesh. J. Adv. Vet. Anim. Res. 6:553-560.

Hill JR, Thompson JA, Perkins NR. 1998. Factors affecting pregnancy rates following laparoscopic insemination of 28,447 Merino ewes under commercial conditions: a survey. Theriogenology 49:697-709.

Horoz H, Kaşikçi G, Ak K, Aklan S, Sonmez C. 2003. Controlling the breeding season using melatonin and progestagen in Kivircik ewes. Turk. J. Vet. Anim. Sci. 27:301-305.

Kershaw CM, Scaramuzzi R, Pitsillides AA, Wheeler-Jones CPD, McGowan MR, Khalid M. 2005. Changes in the cervical extracellular matrix of the sheep during the oestrous cycle. In: Biennial Joint Meeting of the UK Fertility Societies, Programme and Abstract Book, University of Warwick, Coventry UK, pp. 54.

Kusakari N, Ohara M, Mori Y. 1995. Seasonal variation in the timing of estrous behavior, LH surge and ovulation following the treatment with progesterone and PMSG in Suffolk ewes. J. Reprod. Dev. 41:249-254.
Kusina NT, Tarwirei, Hamudikuwanda H, Agumba G, Mukwena J. 2000. A comparison of the effects of progesterone sponges and ear implants, PGF2alpha, and their combination on efficacy of estrus synchronization and fertility of Mashona goat does. Theriogenology 53:1567-1580.

Kwon DJ, Im SK, Kim H, Lee HK, Song KD. 2017. Estrus synchronization and pregnancy rate using ovsynch method in Uganda dairy farms. J. Emb. Trans. 32:159-163.

Langford GA, Marcus GJ, Batra TR. 1983. Seasonal effects of PMSG and number of inseminations on fertility of progestogen-treated sheep. J. Anim. Sci. 57:307-312.

Leethongdee S, Khalid M, Bhatti A, Ponglowhapan S, Kershaw CM, Scaramuzzi RJ. 2007. The effects of the prostaglandin E analogue Misoprostol and follicle-stimulating hormone on cervical penetrability in ewes during the peri-ovulatory period. Theriogenology 67:767-777.

Lim HJ and Yoon HB. 2018. Investigation of relation between the ovulation confirmation and conception rate in dairy cattle. J. Emb. Trans. 33:55-59.

Noakes DE. 2001. Normal oestrous cycles. In: Noakes DE, Parkinson TJ, England GCW, Arthur GH. (Eds.), Arthur's Veterinary Reproduction and Obstetrics. Saunders, London, pp. 3.

Rashidi M and Cedden F. 2013. Trans-cervical artificial insemination in ewes during out of breeding season. Maced. J. Anim. Sci. 3:143-146.

Rezác P. 2008. Potential applications of electrical impedance techniques in female mammalian reproduction. Theriogenology 70:1-14.

Salamon S and Maxwell WMC. 1995. Frozen storage of ram semen II. Causes of low fertility after cervical insemination and methods of improvement. Anim. Reprod. Sci. 38:1-36.

Talukder MRI, Hasan M, Rosy TA, Bari FY, Juyena NS. 2018. Monitoring vaginal electrical resistance, follicular waves, and hormonal profile during oestrous cycle in the transition period in Bangladeshi sheep. J. Vet. Res. 62:571-579.

Theodosiadou E, Amiridis GS, Tsiligianni T. 2014. Relationship between electrical resistance of cervical mucus and ovarian steroid concentration at the time of artificial insemination in ewes. Reprod. Biol. 14:234-237.

Timurkan H and Yildiz H. 2005. Synchronization of oestrus in Hamadani ewes. The use of different PMSG doses. Bull. Vet. Inst. Pulawy. 49:311-314.

Tsiligianni T. 2017. Induction of oestrus in ewes of the rare Greek breeds Skopelos, Zakynthos, Kymi- electrical resistance of cervical mucous. J. Hellenic Vet. Med. Soc. 65:2330.

Windsor DP. 1995. Factors influencing the success of transcervical insemination in Merino ewes. Theriogenology 43:1009-1018.

Yenikoye A. 1984. [Annual variations in estrual behavior, rate and possibilities for ovulation in Peulh ewes from Niger]. Reprod. Nutr. Dev. 24:11-19. French. 